Journal of

Back and

Musculoskeletal

Rehabilitation

Journal of Back and Musculoskeletal Rehabilitation 8 (1997) 7

\title{
American Academy of Disability Evaluating Physicians: history, mission and goals ${ }^{1}$
}

\section{History}

The American Academy of Disability Evaluating Physicians (AADEP) is a not for profit national, professional membership organization chartered in 1987 and incorporated in the state of Illinois in 1989.

The founders of the Academy were dissatisfied and frustrated by the inadequate state of disability evaluation. They advocated for uniform disability assessment methods and the development of uniform standards for the evaluation of impairment.

AADEP is a multi-disciplinary medical organization of medical specialists who evaluate disabled persons in their respective fields.

\section{Mission}

To advance the medical science of disability evaluation by:

- fostering and developing the medical science of disability evaluation;

\footnotetext{
${ }^{1}$ From the mission statement of the AADEP.
}

- conducting research and developing standards of disability evaluation;

- recognizing physicians who meet and maintain specific qualifications; and

- meeting the educational needs of federal and state industrial commissions, departments of labor or rehabilitation, and other governmental agencies in connection with disability evaluation and impairment rating.

Goals

- Develop, augment and support defining of roles and understanding of the responsibilities of Doctors of Medicine and Doctors of Osteopathy in the performance of Disability Evaluations.

- Establish scientifically-based methods for assessment of disability.

- Establish and supervise training in this specialized area of medical practice.

- Promote, attain and maintain competence in Disability Evaluation.

- Foster research in the field of Disability Evaluation.

- Promote scholarly and educational endeavors in the field of Disability Evaluation. 